\title{
Identification and Characterization of Equine Blood Plasmacytoid Dendritic Cells
}

Ziegler Anja ${ }^{\mathrm{a}}$, Marti Eliane ${ }^{\mathrm{a} *}$, Summerfield Artur ${ }^{\mathrm{b}, \mathrm{c}}$, Baumann Arnaud $^{\mathrm{c}}$

${ }^{\text {a }}$ Department of Clinical Research and Veterinary Public Health, Vetsuisse Faculty, University of Bern, Länggassstrasse 124, Bern, Switzerland.

${ }^{\mathrm{b}}$ Institute of Virology and Immunology, Sensemattstrasse 293, Mittelhäusern, Switzerland.

${ }^{c}$ Department of Infectious Diseases and Pathobiology (DIP), Vetsuisse Faculty, University of Bern, Länggassstrasse 122, Bern, Switzerland.

*Correspondence: Eliane Marti, Division of Clinical Research, Department of Clinical Research-VPH, Vetsuisse Faculty, University of Bern. Länggassstrasse 124, PO Box 3001 Bern, Switzerland.

Email: eliane.marti@vetsuisse.unibe.ch 


\begin{abstract}
Dendritic cells (DC) are antigen-presenting cells that can be classified into three major cell subsets: conventional DC1 (cDC1), cDC2 and plasmacytoid DCs (pDC), none of which have been identified in horses. Therefore, the objective of this study was to identify and characterize DC subsets in equine peripheral blood, emphasizing on pDC. Surface marker analysis allowed distinction of putative DC subsets, according to their differential expression of CADM-1 and MHC class II. Equine pDC were found to be Flt3 ${ }^{+} \mathrm{CD} 4^{\text {low }} \mathrm{CD} 13^{-} \mathrm{CD} 14^{-}$ CD172a $\mathrm{a}^{-}$CADM-1'MHCII ${ }^{\text {low }}$. The weak expression of CD4 on equine pDC contrasts with findings in several other mammals. Furthermore, pDC purified by fluorescence-activated cell sorting were found to be the only cell subset able to produce large amounts of IFN- $\alpha$ upon TLR9-agonist stimulation. The pDC identity was confirmed by demonstrating high-levels of PLAC8, RUNX2 and TCF4 expression, showing pDC-restricted expression in other mammals.
\end{abstract}

Keywords: horse, dendritic cell subset, plasmacytoid dendritic cell.

Abbreviations: ODN, oligodeoxynucleotides; DC, dendritic cells; cDC, conventional DC; FMO, fluorescence minus one; Flt3, fms-like tyrosine kinase 3; Flt3L, Flt3 ligand; IFN, interferon; MoDC, monocyte-derived DC; pDC, plasmacytoid DC; PBMC, peripheral blood mononuclear cells. 


\section{Introduction}

Dendritic cells (DC) represent the professional antigen-presenting cells of the immune system and are essential regulators of immunity and tolerance (Banchereau and Steinman, 1998). They can be further categorized into conventional DC (cDC), which are responsible for antigen presentation and induction of T-cell responses, and plasmacytoid DC (pDC) representing the most potent type I interferon (IFN) producing cell, able to efficiently sense microbial nucleic acid (Liu, 2005). Conventional DC consist of at least two phenotypically distinct subsets stimulating particular T-cell responses (Schlitzer and Ginhoux, 2014). The murine $\mathrm{CD} 8 \alpha^{+} /$human $\mathrm{CD} 141^{+}$cells comprise the $\mathrm{cDC} 1$ subset, specialized in crosspresentation of antigens to CD ${ }^{+}$T-cells and stimulating Th1 immunity (Bachem et al., 2010; Jongbloed et al., 2010). The cDC2 subset was identified as murine CD11 ${ }^{+} /$human $\mathrm{CD} 1 \mathrm{c}^{+}$ cells (Haniffa et al., 2013), and is particularly capable to stimulate Th2 and Th17 immunity (Dutertre et al., 2014; Tussiwand and Gautier, 2015). Both pDC and cDC arise from a common DC progenitor in the bone marrow (Liu and Nussenzweig, 2010; Onai et al., 2007) and are dependent on the growth factor fms-like tyrosine kinase 3 ligand (Flt3L) for their development and differentiation (Karsunky et al., 2003; Schmid et al., 2010). Accordingly, all DC subsets express Flt3 receptor (CD135).

A number of reports described the presence of distinct cDC subpopulations in veterinary species, including pigs (Guzylack-Piriou et al., 2010; Maisonnasse et al., 2015; Summerfield et al., 2015; Auray et al., 2016, submitted), cattle (Howard et al., 1999; Renjifo et al., 1997) and sheep (Contreras et al., 2010; Pascale et al., 2008). Additionally, pDC have been identified in pig (Summerfield et al., 2003), in cattle (Reid et al., 2011) and in sheep (Pascale et al., 2008).

However, neither cDC nor pDC have been described in horses. Studies that have been performed to date, resorted to the use of monocyte-derived dendritic cells (MoDC) (Cavatorta et al., 2009; Mauel et al., 2006; Moyo et al. 2013). Although MoDC possess many functional 
attributes consistent with DC (Sallusto and Lanzavecchia, 1994), they do not represent bona fide DC based on their ontogeny. Nevertheless, many in vivo studies report MoDC as a distinct subtype of inflammatory monocytic cell, sharing some features with cDC in terms of antigen presentation (Guilliams et al., 2014; Schlitzer et al., 2015). Consequently, for advances in immunological research in horses, it is essential to gain more information on equine bona fide DC.

The aim of the present study was to phenotypically characterize equine blood DC and functionally identify pDC in healthy horses. As a first step, appropriate cell surface markers which were either equine-specific or shown to cross-react with the equine system were used to identify distinct cell subsets in equine peripheral blood mononuclear cells (PBMC) by flow cytometry. Based on the comparative approach used by Summerfield et al. (2015), a first classification of equine DC subsets is proposed. The identity of purified $\mathrm{pDC}$ was further confirmed by a robust IFN- $\alpha$ production upon TLR9-stimulation as well as by a high expression of pDC-specific transcripts.

\section{Methods}

\subsection{Isolation of peripheral blood mononuclear cells from healthy horses}

Blood samples were collected from the jugular vein of eleven healthy horses (age $=4-21$ years) using sterile glass bottles supplemented with 5000 I.U./ml heparin (Liquemin ${ }^{\circledR}$, Drossapharm AG, Basel, Switzerland) or Sodium-Heparin containing vacutainers (Vacuette ${ }^{\circledR}$;

Greiner, St.Gallen, Switzerland). The study was approved by the Animal Experimental Committee of the Canton of Berne and Vaud, Switzerland (No. BE 51/13). PBMC were isolated by density gradient centrifugation over Biocoll $(\rho=1.077 \mathrm{~g} / \mathrm{ml}$, Biochrom GmbH, Berlin, Germany) as described (Hamza et al., 2007).

\subsection{Production of recombinant bovine Flt3 Ligand}


Bovine instead of equine Flt3L was used because the complete equine Flt3L gene sequence is still unknown. The partial equine Flt3L sequence (Genbank: XP_005596791.1) exhibits 73\% amino acid sequence homology to bovine Flt3L. Bovine Flt3L (NCBI NM_181030.2) was produced as previously described (Guzylack-Piriou et al., 2010) and was originally employed for another study (Baumann et al., unpublished data). Briefly, after deletion of the stop codon, the Flt3L sequence was flanked by HindIII and XbaI restriction sites and was chemically synthesized in pUC57 plasmid (GenScript, Piscataway, NJ, USA). After HindIII and XbaI digestion, Flt3L was ligated in the pEAK8-His expression vector. The TOP10 Chemically Competent E. coli cells (Invitrogen, USA) were transformed with the plasmid pEAK8-His containing the bovine Flt3L. For final recombinant production of bovine Flt3L, HEK 293 cells were transfected with pEAK8-His-Flt3L using X-tremeGENE 9 following the manufacturer's instructions (Roche, Basel, Switzerland). After 5 days, supernatant was collected and expression of recombinant bovine Flt3L was assessed by western blot using an anti-his-HRP antibody (cat. no. 130-092-785, Miltenyi Biotec; Antibody Register: AB_1103231). The reaction was visualized with a WesternBright ECL Western blotting detection kit (Advansta Inc., Menlo Park, CA, USA) and a CCD-LAS3000 camera (Fuji Film) (Fig. S1).

\subsection{Surface marker analysis by flow cytometry}

PBMC from three horses were transferred to $5 \mathrm{ml}$ FACS tubes at $3 \times 10^{6}$ cells per tube. First, a blocking step was performed using Chrome Pure whole mouse IgG (Jackson Immunoresearch, West Grove, PA, USA). All incubations were performed for 20 min on ice, followed by washing with PBS and centrifugation at $500 \mathrm{x}$ g for $5 \mathrm{~min}$. Briefly, cells were incubated with recombinant bovine Flt3L, followed by labelling with a PE-conjugated anti-his antibody (clone GG11-8F3.5.1, cat-no 130-092-691; Miltenyi Biotec; Antibody Register: AB_1103227). Anti-human CADM-1 (cat no. CM004-3, MBL International Corporation; 
Antibody Registry: AB_592783), shown to specifically bind to the CADM-1 molecule in many mammalian species (Contreras et al., 2010; Dutertre et al., 2014), was detected by a secondary goat biotinylated anti-chicken antibody (cat no 103-065-155, Jackson Immunoresearch; Antibody Registry: AB_2337383), followed by labelling using Brilliant Violet (BV)421 conjugated to Streptavidin (BD Biosciences, Franklin Lakes, NJ, USA). Other surface markers were stained using the following antibodies: anti-equine CD4 (clone CVS4; cat no MCA1078, Bio-Rad; Antibody Register AB_321274), anti-equine CD13 (clone CVS19; cat no MCA1084GA, Bio-Rad; Antibody Registry: AB_321308), anti-equine MHCII (clone CVS20; cat no MCA1085, BioRad; Antibody Register AB_321618), antiequine CD14 (clone 105; https://courses2.cit.cornell.edu/wagnerlab/research/reagents.htm; Kabithe et al., 2010)), anti-bovine CD172a (clone HR-DH59B; cat no HR-BOV2049; Monoclonal Antibody center, Washington State University; Pullman WA, USA ) showing cross-reactivity with equine cells (Mérant et al., 2009). These monoclonal antibodies were labelled with mouse IgG1 Alexa Fluor 488, 647 or 700 Zenon labelling kits (Thermo Scientific, Waltham MA, USA). Appropriate isotype and fluorescence-minus-one (FMO) controls were used. Finally, cells were resuspended in phosphate buffered saline (PBS) and analysed on a LSRII flow cytometer (BD Biosciences). Automated compensation for spectral overlap of fluorochromes was calculated by the BD FACSDIVA acquisition software (BD Biosciences) based on single-stained PBMC. Data were analysed using FlowJo software 6 (Tree Star Inc. Ashland OR, USA). Gates were set to exclude doublets and lymphocytes based on forward and side scatter characteristics (Fig. 1A). Within this cell population, a further gate was set on $\mathrm{Flt}^{+} / \mathrm{CD} 14^{\text {low }}$ cells, based on isotype and fluorescence minus one (FMO) controls. This gating strategy was used for all flow cytometry experiments.

\subsection{PBMC stimulation for IFN- $\alpha$ production}


PBMC were isolated as described above and suspended in RPMI 1640 medium with HEPES and L-glutamine (Gibco, Life Technologies Ltd, Paisley UK) supplemented with 1\% penicillin and streptomycin (Gibco), 1\% MEM vitamins, $1 \%$ Na pyruvate, $1 \%$ Non-essential amino acids (all Biochrom $\mathrm{GmbH}$ ) and 10\% inactivated horse serum (Ziegler et al. 2016, in revision) at a density of $2 \times 10^{5}$ cells per $200 \mu \mathrm{l}$ medium in a 96-well round-bottom cell culture plate (Sarstedt, Nümbrecht, Germany). Cells were cultured for $24 \mathrm{~h}$ in the presence of $5 \mu \mathrm{g} / \mathrm{ml}$ of the synthetic TLR9 agonist Type C CpG-oligodeoxynucleotides (ODN) D-SL03 (InvivoGen, San Diego, CA, USA) or of equine herpesvirus-1 (EHV-1; MOI of 0.04 TCID 50 / cell, EHV1-V144/64, kindly supplied by Prof. Reto Zanoni from the Institute for Virology and Immunology, Vetsuisse Faculty, University of Berne, Switzerland). Thereafter, cell culture supernatants were collected and stored at $-80^{\circ} \mathrm{C}$ until used.

\subsection{Enrichment of $\mathrm{pDC}$ by depletion of $\mathrm{PBMC}$ from $\mathrm{CD5}^{+}$and $\mathrm{CD14}^{+}$cells}

PBMC were depleted of $\mathrm{CD}^{+}$and $\mathrm{CD} 14^{+}$cells by magnetic separation (MACS technology, Miltenyi Biotec $\mathrm{GmbH}$ ) according to standard protocols by the manufacturer, using a monoclonal anti-equine CD5 antibody (clone CVS5; cat no MCA1079GA, Bio-Rad; Antibody Register: AB_321382) and anti-equine CD14 (clone 105, Kabithe et al., 2010). Briefly, PBMC were first incubated with anti-CD5 and anti-CD14 simultaneously and, after a washing step, with secondary goat anti-mouse micro beads. Cells were then separated on a LD column (Miltenyi Biotec GmbH). After washing, the CD5/ CD14-depleted (purity > 75\%) and CD5/ CD14-enriched (purity > 95\%) fraction were stimulated with CpG-ODN or EHV-1 as described above for $24 \mathrm{~h}$ and supernatants were harvested and stored at $-80^{\circ} \mathrm{C}$ until used.

\subsection{Sorting experiments}

Flt $3^{+}$cells from three horses were enriched from PBMC by MACS separation as described above, using the recombinant bovine Flt3L bound by an anti-his antibody conjugated to PE 
and ultra-pure anti-PE microbeads (both Miltenyi Biotec GmbH). The magnetic separation was performed at $4^{\circ} \mathrm{C}$. Following Flt3-enrichment, cells were stained for expression of CD14, CADM-1 and MHCII as mentioned above. Using a BD FACSAria sorter, Flt $3{ }^{+} \mathrm{CD} 14^{\text {low }}$ cells were gated. MHCII ${ }^{\text {low }} / \mathrm{CADM}-1^{-}, \mathrm{MHCII}^{\text {high }} / \mathrm{CADM}-1^{\text {low }}$ and MHCII ${ }^{\text {high }} / \mathrm{CADM}-1^{+}$ subpopulations were identified and sorted. Sorted cells were used for subsequent stimulation with the TLR9 agonist CpG-ODN D-SL03, as described above, using 20’000 cells/ $100 \mu 1$ medium per well. The remaining cells were resuspended in $1 \mathrm{ml}$ Isol-RNA Lysis Reagent (5 Prime, Hilden, Germany) and kept at $-80^{\circ} \mathrm{C}$ until used.

\subsection{Equine IFN- $\alpha$ ELISA}

For detection of IFN- $\alpha$ in cell culture supernatants, we used an equine IFN- $\alpha$ ELISA (kindly supplied by Dr. Bettina Wagner, Cornell University, Ithaca NY, USA). The assay was performed as described (Wagner et al., 2008). Briefly, anti-IFN- $\alpha$ (clone 29B; https://courses2.cit.cornell.edu/wagnerlab/research/reagents.htm) was used for coating of the plates at a concentration of $5 \mu \mathrm{g} / \mathrm{ml}$. rIFN-a/IgG4 supernatant $(85 \mathrm{ng} / \mathrm{ml})$ was serially diluted two-fold, ranging from $42.5 \mathrm{ng} / \mathrm{ml}-0.66 \mathrm{ng} / \mathrm{ml}$, to obtain a standard curve. Cell culture supernatants of stimulated cells were tested in duplicates at a 1:2 dilution. For detection, biotinylated anti-IFN- $\alpha$ (clone 240;

https://courses2.cit.cornell.edu/wagnerlab/research/reagents.htm) was used. This step was followed by incubation with streptavidin-peroxidase and TMB substrate (Sigma-Aldrich $\mathrm{GmbH}$, Buchs, Switzerland). Optical density was measured at $450 \mathrm{~nm}$ on an ELISA Reader (BioTek Instruments Inc., Winooski VT, USA) and IFN- $\alpha$ concentration in the samples was calculated according to the standard curve calculated by the Gen5 software (BioTek Instruments Inc.).

\subsection{Quantitative Reverse-Transcriptase Polymerase Chain Reaction (qRT-PCR)}


For RNA extraction from sorted PBMC fractions, $200 \mu 1$ of chloroform:IAA (49:1; SigmaAldrich $\mathrm{GmbH}$ ) were added to $1 \mathrm{ml}$ of Isol-RNA lysate and tubes were vigorously shaken by hand. After $5 \mathrm{~min}$ incubation at room temperature, samples were centrifuged at 12,000 x $\mathrm{g}$ for $15 \mathrm{~min}$. The aqueous upper phase was subsequently transferred to a fresh tube and $500 \mu \mathrm{l}$ of $100 \%$ isopropanol were added. Precipitated RNA was then loaded onto a spin column from RNeasy Mini Kit (Qiagen GmbH, Hilden, Germany) and purification was performed according to manufacturer's instructions. RNA was eluted in $40 \mu$ l of RNAse-free $\mathrm{H}_{2} \mathrm{O}$. Each sample was quantified spectrophotometrically (NanoDrop 1000, Thermo Scientific) and stored at $-80{ }^{\circ} \mathrm{C}$ until used. A total of $9 \mu 1$ of RNA was employed to synthesize cDNA using GoScript ${ }^{\mathrm{TM}}$ Reverse Transcription system (Promega, Madison WI, USA) following manufacturer's instructions. Expression of PLAC8, RUNX2, TCF4 and BACT were quantified by qPCR using the GoTaq ${ }^{\circledR}$ qPCR Master Mix (Promega) with the primers listed in the table $\mathrm{S} 1$. The reaction was performed in a total volume of $25 \mu \mathrm{l}$ in the 7500 real-time PCR system (Applied Biosystems, Foster City, CA, USA) under the following fast-cycle amplification conditions: $2 \mathrm{~min}$ at $95^{\circ} \mathrm{C}$, followed by 40 cycles of denaturation at $95^{\circ} \mathrm{C}$ for 3 seconds followed by annealing/ extension at $58^{\circ} \mathrm{C}$ for 30 seconds. The specificity of each primer pair was confirmed in melting-curve analysis and primer efficiency reached $>90 \%$ by using serial cDNA dilution as template. Relative expression was normalized to the housekeeping gene $B A C T$ expression and $\triangle \mathrm{Ct}$ was calculated as: $2^{-\mathrm{Ct} \text { gene }} / 2^{\text {-Ct housekeeping gene }}$.

\subsection{Statistical Analysis}

Statistical analysis was carried out using the software program NCSS8. As the data were not normally distributed, a non-parametric Wilcoxon (signed rank) test was used to compare levels of secreted IFN- $\alpha$ between stimulation conditions. $P$-values $\leq 0.05$ were considered significant. 


\section{Results and Discussion}

\subsection{Surface marker expression of equine dendritic cell subsets}

Since the Flt3 expression on DC is well conserved in mammals (Karsunky et al., 2003; Schmid et al., 2010; Summerfield et al., 2015), Flt3L constitutes a valuable tool to identify DC in a mixed cell population. Orthologous bovine Flt3L was shown to bind to a small heterogeneous population of equine PBMC $(0.42-0.85 \%)$ which did not express CD14 at all, or at very low levels only (Fig 1B).

Within the $\mathrm{Fl} 3^{+} / \mathrm{CD} 14^{\text {low }}$ gate, three subpopulations (P4, P5 and P6) could be further identified based on the differential expression of MHCII and CADM-1 (Fig. 1C). P4 was found to express the lowest levels of CD172a, while P5 expressed high levels, comparable to monocytes (Fig. 1D). None of the subsets was found to express high levels of CD4 (Fig. 1D). Interestingly, $\mathrm{CD} 13$ was co-expressed with $\mathrm{CADM}-1$ on a population within $\mathrm{Flt} 3{ }^{+} \mathrm{CD} 14^{\text {low }}$ cells (Fig. 1D). In alignment with other species and considering that CADM-1, CD13, Flt3 and CD172a represent cell surface receptors with a species-conserved expression (Summerfield et al., 2015), we propose that equine $\mathrm{cDC} 1$ can be identified as $\mathrm{Flt}^{+} \mathrm{CD}^{-}$ $\mathrm{CD} 13^{+} \mathrm{CD} 14^{\text {low }} \mathrm{CD} 172 \mathrm{a}^{-} \mathrm{CADM}-1^{+} \mathrm{MHCII}{ }^{\text {high }}$ cells, while equine $\mathrm{cDC} 2$ would be Flt $3^{+} \mathrm{CD} 4-$ CD13-CD14 ${ }^{\text {low }} \mathrm{CD} 172 \mathrm{a}^{+} \mathrm{CADM}-1^{\text {low }} \mathrm{MHCII}{ }^{\text {high }}$. This will require future confirmation for example by employing transcriptional profiling of the sorted populations. As the present study was focusing on $\mathrm{pDC}$ we continued our experimentation focusing on the $\mathrm{Flt} 3^{+} \mathrm{CD} 4^{-} \mathrm{CD}^{-} 3^{-}$ CD14 CD172a-CADM-1-MHCII ${ }^{\text {low }}$ subset as a possible candidate for $\mathrm{pDC}$.

\subsection{Functional identification of equine pDC}

As a first experiment, PBMC from eleven healthy horses were stimulated with the synthetic TLR9 agonist type C CpG-ODN or with EHV-1 and the amount of IFN- $\alpha$ in the supernatants was quantified by ELISA. A significant IFN- $\alpha$ induction could be observed in cells stimulated with both EHV-1 and CpG-ODN compared to unstimulated cells (Fig.2A). Intriguingly, while 
an induction of IFN- $\alpha$ by EHV-1 was shown in PBMC from all horses, five out of the eleven tested horses were non-responsive to stimulation by CpG-ODN (Fig. 2A). The strongest induction of IFN- $\alpha$ in response to CpG-ODN was detectable with PBMC of horses, which also released the highest quantities of IFN- $\alpha$ in response to EHV-1. We speculate that there was a higher number of pDC present in the PBMC of these horses. On the other hand, EHV-1 contains a number of pathogen-associated molecular patterns. It may have been able to induce IFN- $\alpha$ production through a broader stimulation of various pathways, possibly also in other cells than pDC, thus inducing IFN- $\alpha$ secretion also in PBMC of horses which were unresponsive to $\mathrm{CpG}-\mathrm{ODN}$ stimulation. In order to enrich the pDC population, PBMC were depleted of $\mathrm{CD}^{+} \mathrm{T}$-cells and CD14+ monocytes. Whereas CD5-/CD14-depleted PBMC released high levels of IFN- $\alpha$, no response was observed in CD5-/CD14-enriched fractions after CpG or virus stimulation (Fig. S2). These data indicate that the pDC do not express CD5 and CD14.

To further confirm pDC identity and to obtain sufficient cell numbers for FACS sorting, Flt $3^{+}$ cells were enriched by MACS sorting, resulting in $7 \% \mathrm{Flt}^{+}$cells (range $3-10.1 \%$ ), which represented an 11-fold enrichment (data not shown). Similar to what we observed with PBMC, three cell subsets could be clearly distinguished in the CD14 $4^{\text {low }} / \mathrm{Flt} 3^{+}$fraction with regard to MHCII and CADM-1 expression (Fig. 2B). They were subsequently sorted by FACS. Stimulation of PBMC, Flt3 MACS-enriched and Flt3 MACS-depleted fractions with CpG-ODN revealed distinct differences in IFN- $\alpha$ induction, confirming the presence of pDC in the Flt $3^{+}$cells (Fig. 2C). Slight increase in IFN- $\alpha$ secretion was observed in the Flt3 MACS-enriched compared to PBMC (median; range $=14.1 ; 9.1-22.2 \mathrm{ng} / \mathrm{ml}$ and 9.7; 0.23 $11.9 \mathrm{ng} / \mathrm{ml}$, respectively), whereas no IFN- $\alpha$ production could be detected in the Flt3-depleted fraction. As hypothesized, IFN- $\alpha$ was solely produced by the P4 fraction of putative pDC (median 20.2; range $15.9-50.3 \mathrm{ng} / \mathrm{ml}$ ), with no IFN- $\alpha$ production detected in the other two subsets, indicating that the $\mathrm{P} 4$ subset would represent $\mathrm{pDC}$. 
Recent breakthroughs in transcriptomic profiling of DC subsets have revealed cell-type specific transcripts some of which were conserved between species (Miller et al., 2012; Shay et al. 2013). Thus, new possibilities have opened up for characterization of DC subsets in veterinary species (Summerfield et al., 2015; Vu Manh et al., 2015). Moreover, expression analysis of genes known to be specifically expressed in pDCs in other species including PLAC8 (=C-15) (Rissoan et al., 2002), RUNX2 (Sawai et al., 2013) and TCF4 (= E2-2) (Cisse et al., 2008) revealed a high expression in the putative equine pDC fraction (Fig. 2D). While RUNX2 levels were found to be low in the P5 cell fraction, no expression of the other transcripts was detected, indicating that PLAC8 and TCF4 represent pDC-specific transcripts also in horses. We found a similar restricted expression of these genes in porcine pDC (Auray and Summerfield, unpublished results). While the function of PLAC8 on pDC is unknown, $R U N X 2$ and in particular TCF4 represent essential transcription factors for their development (Sawai et al., 2013; Cisse et al., 2008). Considering the transcriptions factors controlling immune cell development are well conserved, this data confirms that the Flt3 ${ }^{+} \mathrm{CD} 4^{-} \mathrm{CD} 13^{-}$ CD14-CD172a-CADM-1-MHCII ${ }^{\text {low }} \mathrm{P} 4$ subset represents or contains equine $\mathrm{pDC}$. In summary, we have identified equine $\mathrm{pDC}$ and propose a basis for further characterization of equine blood $\mathrm{cDC}$. Alignment of the phenotype of equine $\mathrm{pDC}$ with other species highlighted some intriguing differences, such as a very low or lacking expression of CD4, contrasting with several other mammals (Summerfield et al., 2015). Considering the importance of DC in many immunological processes, future work should follow to identify DC-subset specific transcripts, which will be the basis to establish reagents for equine DC characterization.

\section{Conflicts of interest}

The authors declare no conflicts of interest 


\section{Acknowledgements}

We are grateful to Dr. Andreas Zurbriggen, Department of Clinical Research and Veterinary Public Health, Vetsuisse Faculty, University of Bern for his continuous support. We would like to thank Dr. Bettina Wagner at the Department of Population Medicine and Diagnostic Sciences, College of Veterinary Medicine, Cornell University, Ithaca, NY 14853, USA for providing the anti-equine CD14 antibody and the equine IFN- $\alpha$ ELISA, as well as Prof. Reto Zanoni at the Institute for Virology and Immunology, Vetsuisse Faculty, University of Berne, Switzerland for supplying the EHV-1.

\section{Funding}

This work was supported by a grant of the Department of Clinical Research VPH, Vetsuisse Faculty, University of Bern and by the Swiss National Science Foundation grant no. 310030$160196 / 1$. The support was purely financial, the funding sources were not involved in the collection or analysis of data, in the writing of the manuscript, nor in the decision to submit the article for publication. 


\section{References}

Bachem, A., Güttler, S., Hartung, E., Ebstein, F., Schaefer, M., Tannert, A., Salama, A., Movassaghi, K., Opitz, C., Mages, H.W., Henn, V., Kloetzel, P.M., Gurka, S., Kroczek, R.A., 2010. Superior antigen cross-presentation and XCR1 expression define human CD11c+ CD141+ cells as homologues of mouse CD8+ dendritic cells. J. Exp. Med. 207(6), 1273-81.

Banchereau, J., Steinman, R.M., 1998. Dendritic cells and the control of immunity. Nature. 392(6673), 245-52.

Cavatorta, D.J., Erb, H.N., Flaminio, M.J., 2009. Ex vivo generation of mature equinemonocyte-derived dendritic cells. Vet. Immunol. Immunopathol. 131(3-4), 259-67.

Cisse, B., Caton, M.L., Lehner, M., Maeda, T., Scheu, S., Locksley, R., Holmberg, D., Zweier, C., den Hollander, N.S., Kant, S.G., Holter, W., Rauch, A., Zhuang, Y., Reizis, B. 2008. Transcription factor E2-2 is an essential and specific regulator of plasmacytoid dendritic cell development. Cell. 135(1), 37-48.

Contreras, V., Urien, C., Guiton, R., Alexandre, Y., Vu Manh, T.P., Andrieu, T., Crozat, K., Jouneau, L., Bertho, N., Epardaud, M., Hope, J., Savina, A., Amigorena, S., Bonneau, M., Dalod, M., Schwartz-Cornil, I., 2010. Existence of CD8 $\alpha$-like dendritic cells with a conserved functional specialization and a common molecular signature in distant mammalian species. J. Immunol. 185(6), 3313-25.

Dutertre, C.A., Wang, L.F., Ginhoux, F., 2014. Aligning bona fide dendritic cell populations across species. Cell. Immunol. 291(1-2), 3-10.

Guilliams, M., Ginhoux, F., Jakubzick, C., Naik, S.H., Onai, N., Schraml, B.U., Segura, E., Tussiwand, R., Yona, S., 2014. Dendritic cells, monocytes and macrophages: a unified nomenclature based on ontogeny. Nat. Rev. Immunol. 14(8), 571-8. 
Guzylack-Piriou, L., Alves, M.P., McCullough, K.C., Summerfield, A., 2010. Porcine Flt3 ligand and its receptor: generation of dendritic cells and identification of a new marker for porcine dendritic cells. Dev. Comp. Immunol. 34(4), 455-64.

Hamza, E., Doherr, M.G., Bertoni, G., Jungi, T.W., Marti, E., 2007. Modulation of allergy incidence in icelandic horses is associated with a change in IL-4-producing T cells. Int. Arch. Allergy. Immunol. 144(4), 325-37.

Haniffa M, Collin M, Ginhoux F. Ontogeny and functional specialization of dendritic cells in human and mouse. Adv. Immunol. 2013; 120:1-49. Review.

Howard, C.J., Brooke, G.P., Werling, D., Sopp, P., Hope, J.C., Parsons, K.R., Collins, R.A., 1999. Dendritic cells in cattle: phenotype and function. Vet. Immunol. Immunopathol. 72(12), 119-24.

Jongbloed, S.L., Kassianos, A.J., McDonald, K.J., Clark, G.J., Ju, X., Angel, C.E., Chen, C.J., Dunbar, P.R., Wadley, R.B., Jeet, V., Vulink, A.J., Hart, D.N., Radford, K.J., 2010. Human CD141+ (BDCA-3)+ dendritic cells (DCs) represent a unique myeloid DC subset that crosspresents necrotic cell antigens. J. Exp. Med. 207(6), 1247-60.

Kabithe, E., Hillegas, J., Stokol, T., Moore, J., Wagner, B., 2010. Monoclonal antibodies to equine CD14. Vet. Immunol. Immunopathol. 138(1-2), 149-53

Karsunky, H., Merad, M., Cozzio, A., Weissman, I.L., Manz, M.G., 2003. Flt3 ligand regulates dendritic cell development from Flt3+ lymphoid and myeloid-committed progenitors to Flt3+ dendritic cells in vivo. J. Exp. Med. 198(2), 305-13.

Liu, Y.J., 2005. IPC: professional type 1 interferon-producing cells and plasmacytoid dendritic cell precursors. Annu. Rev. Immunol. 23, 275-306. 
Liu, K., Nussenzweig, M.C., 2010. Origin and development of dendritic cells. Immunol. Rev. 234(1), 45-54.

Maisonnasse, P., Bouguyon, E., Piton, G., Ezquerra, A., Urien, C., Deloizy, C., Bourge, M., Leplat, J.J., Simon, G., Chevalier, C., Vincent-Naulleau, S., Crisci, E., Montoya, M., Schwartz-Cornil, I., Bertho, N., 2015. The respiratory DC/macrophage network at steady-state and upon influenza infection in the swine biomedical model.Mucosal Immunol. Epub ahead of print.

Mauel, S., Steinbach, F., Ludwig, H., 2006. Monocyte-derived dendritic cells from horses differ from dendritic cells of humans and mice. Immunology. 117(4), 463-73.

Mérant, C., Breathnach, C.C., Kohler, K., Rashid, C., Van Meter, P., Horohov, D.W., 2009. Young foal and adult horse monocyte-derived dendritic cells differ by their degree of phenotypic maturity. Vet. Immunol. Immunopathol. 131(1-2), 1-8.

Miller, J.C., Brown, B.D., Shay, T., Gautier, E.L., Jojic, V., Cohain, A., Pandey, G., Leboeuf, M., Elpek, K.G., Helft, J., Hashimoto, D., Chow, A., Price, J., Greter, M., Bogunovic, M., Bellemare-Pelletier, A., Frenette, P.S., Randolph, G.J., Turley, S.J., Merad, M., 2012. Immunological Genome Consortium. Deciphering the transcriptional network of the dendritic cell lineage. Nat. Immunol. 13(9), 888-99.

Moyo, N.A., Marchi, E., Steinbach, F., 2013. Differentiation and activation of equine monocyte-derived dendritic cells are not correlated with CD206 or CD83 expression. Immunology. 139(4), 472-83.

Onai, N., Obata-Onai, A., Schmid, M.A., Ohteki, T., Jarrossay, D., Manz, M.G., 2007. Identification of clonogenic common Flt3+M-CSFR+ plasmacytoid and conventional dendritic cell progenitors in mouse bone marrow. Nat. Immunol. 8(11), 1207-16. 
Pascale, F., Contreras, V., Bonneau, M., Courbet, A., Chilmonczyk, S., Bevilacqua, C., Epardaud, M., Niborski, V., Riffault, S., Balazuc, A.M., Foulon, E. ,Guzylack-Piriou, ～L., Riteau, B., Hope, J., Bertho, N., Charley, B., Schwartz-Cornil, I., 2008. Plasmacytoid dendritic cells migrate in afferent skin lymph. J. Immunol. 180(9), 5963- 72.

Reid, E., Juleff, N., Gubbins, S., Prentice, H., Seago, J., Charleston, B., 2011. Bovine plasmacytoid dendritic cells are the major source of type I interferon in response to footand-mouth disease virus in vitro and in vivo. J. Virol. 85(9), 4297-308.

Renjifo, X., Howard, C., Kerkhofs, P., Denis, M., Urbain, J., Moser, M., Pastoret, P.P., 1997. Purification and characterization of bovine dendritic cells from peripheral blood. Vet. Immunol. Immunopathol. 60(1-2), 77-88.

Rissoan, M.C., Duhen, T., Bridon, J.M., Bendriss-Vermare, N., Péronne, C., de Saint, Vis, B., Brière, F., Bates, E.E., 2002. Subtractive hybridization reveals the expression of immunoglobulin-like transcript 7, Eph-B1, granzyme B, and 3 novel transcripts in human plasmacytoid dendritic cells. Blood. 100(9), 3295-303.

Sallusto, F., Lanzavecchia, A., 1994. Efficient presentation of soluble antigen by cultured human dendritic cells is maintained by granulocyte/macrophage colony-stimulating factor plus interleukin 4 and downregulated by tumor necrosis factor alpha. J. Exp. Med. 179(4), 1109-18.

Sawai, C.M., Sisirak, V., Ghosh, H.S., Hou, E.Z., Ceribelli, M., Staudt, L.M., Reizis, B., 2013. Transcription factor Runx 2 controls the development and migration of plasmacytoid dendritic cells. J. Exp. Med. 210(11), 2151-9.

Schlitzer, A., Ginhoux, F., 2014. Organization of the mouse and human DC network. Curr. Opin. Immunol. 26, 90-9. 
Schlitzer, A., McGovern, N., Ginhoux, F., 2015. Dendritic cells and monocyte-derived cells: Two complementary and integrated functional systems. Semin. Cell. Dev. Biol. 41, 9- 22.

Schmid MA, Kingston D, Boddupalli S, Manz MG. Instructive cytokine signals in dendritic cell lineage commitment. Immunol Rev. 2010; 234(1):32-44.

Shay, T., Jojic, V., Zuk, O., Rothamel, K., Puyraimond-Zemmour, D., Feng, T., Wakamatsu, E., Benoist, C., Koller, D., Regev, A., 2013. ImmGen Consortium. Conservation and divergence in the transcriptional programs of the human and mouse immune systems. Proc. Natl. Acad. Sci. USA. 110(8), 2946-51.

Summerfield, A., Guzylack-Piriou, L., Schaub, A., Carrasco, C.P., Tâche, V., Charley, B., McCullough, K.C., 2003. Porcine peripheral blood dendritic cells and natural interferonproducing cells. Immunology. 110(4), 440-9.

Summerfield, A., Auray, G., Ricklin, M., 2015. Comparative dendritic cell biology of veterinary mammals. Annu. Rev. Anim. Biosci. 3, 533-57.

Tussiwand, R., Gautier, E.L., 2015. Transcriptional Regulation of Mononuclear Phagocyte Development. Front. Immunol. 2015. 6, 533.

Vu Manh, T.P., Bertho, N., Hosmalin, A., Schwartz-Cornil, I., Dalod, M., 2015. Investigating Evolutionary Conservation of Dendritic Cell Subset Identity and Functions. Front. Immunol. 6, 260.

Wagner, B., Hillegas, J.M., Flaminio, M.J., Wattrang, E., 2008. Monoclonal antibodies to equine interferon-alpha (IFN-alpha): new tools to neutralize IFN-activity and to detect secreted IFN-alpha. Vet. Immunol. Immunopathol. 125(3-4), 315-25.

\section{Figure Legends}




\section{Figure 1.}

Phenotype of Flt $3^{+}$cells in equine PBMC. (A) Gating strategy to remove doublets and include $\mathrm{FSC}^{\text {high }} / \mathrm{SSC} \mathrm{Cigh}^{\text {high }}$ large cells. A total number of 250 '000 cells were acquired. (B) Within the single, large cell gate, based on the fluorescence minus one (FMO) control, a gate on Flt $3^{+} \mathrm{CD} 14^{-}$cells was set. (C) Identification of three putative DC subpopulations based on MHCII and CADM-1 expression within Flt $3^{+}$CD14- gated cells. (D) Histograms showing the expression levels of CD172a, CD4 and CD13 in P4 (red; pDC), P5 (blue; cDC2) and P6 (orange; cDC1) compared to PBMC (grey). Data are shown for one representative animal out of three.

\section{Figure 2.}

Characterization of equine $\mathrm{pDC}$. (A) IFN- $\alpha$ secretion by equine PBMC upon stimulation with CpG-ODN $(5 \mu \mathrm{g} / \mathrm{ml})$ or EHV-1 (MOI of 0.04 TCID $50 /$ cell). Samples were tested in duplicates and results are displayed as mean optical density (OD) measured at $450 \mathrm{~nm}$. Each symbol indicates a separate horse with red lines indicating the median. A non-parametric paired sample Wilcoxon signed rank test was performed to compare the stimulation conditions. Pvalues $\leq 0.05$ were considered statistically significant as indicated by asterisks. (B) Gating strategy of putative DC subsets within Flt3-enriched cells which were employed for FACS. A gate was set on the $\mathrm{Flt} 3^{+} / \mathrm{CD} 14^{\text {low }}$ cells. The three distinct cell populations in the CADM-1/ MHCII plot were then gated and sorted. (C) IFN- $\alpha$ was detected in cell culture supernatants of PBMC (white background), Flt3-enriched and Flt3-depleted fractions, respectively (light green background) as well as FACS-sorted DC subsets (red background) stimulated with 5 $\mu \mathrm{g} / \mathrm{ml} \mathrm{CpG-ODN}$ for 24h. Each symbol represents an individual horse with red lines indicating the median. Samples were tested in duplicates and results are displayed as $\mathrm{ng} / \mathrm{ml}$. (D) Relative expression of PLAC8, RUNX2 and TCF4 transcripts in the sorted populations $\mathrm{P} 4$, P5 and P6. The expression was normalized to the housekeeping gene BACT. Bars show the 
mean $+/$ - SD of an independent experiment performed in duplicate. One representative sorting out of three is shown. 


\section{Figure}

A

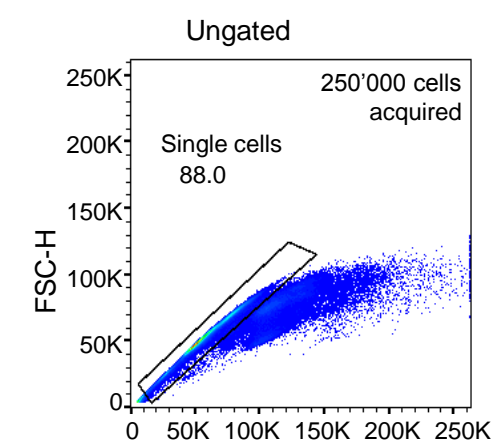

C

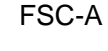

CD14-Flt3+

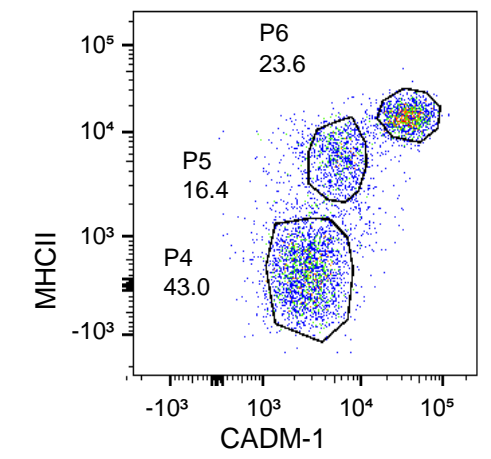

B
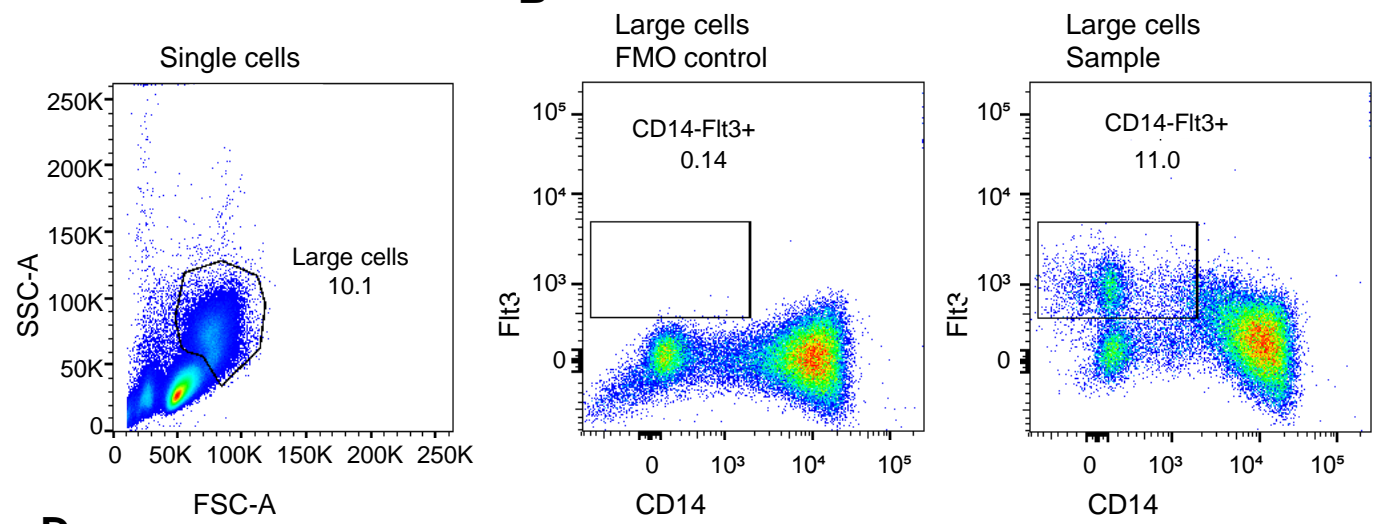

D

FSC-A

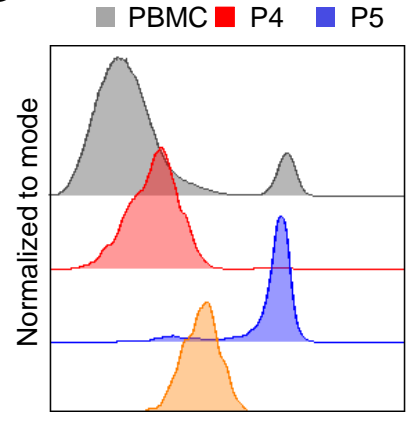

CD172a

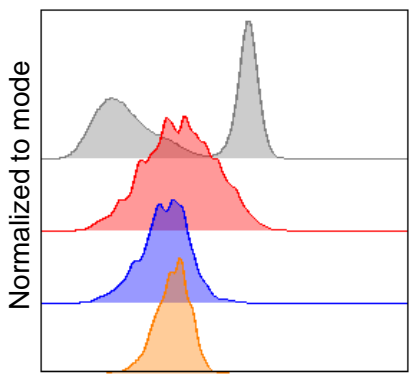

CD4

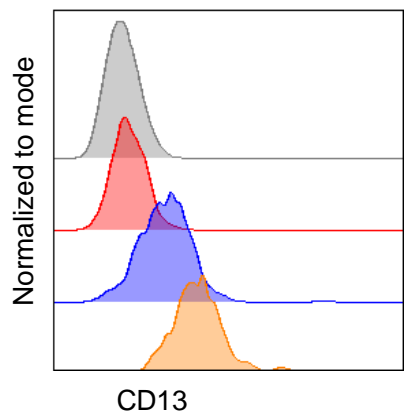


A

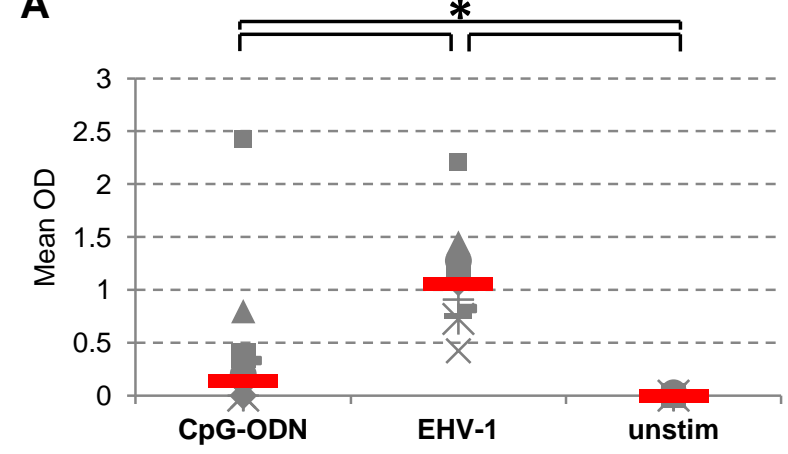

C

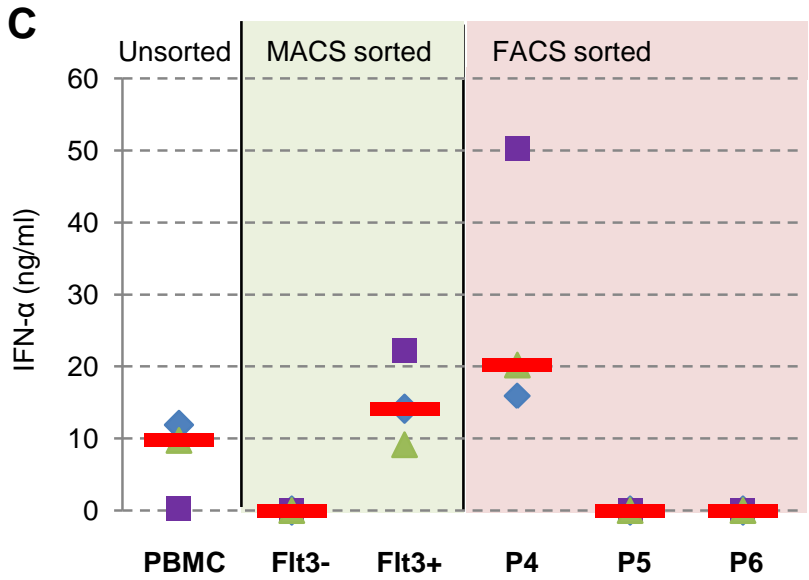

B

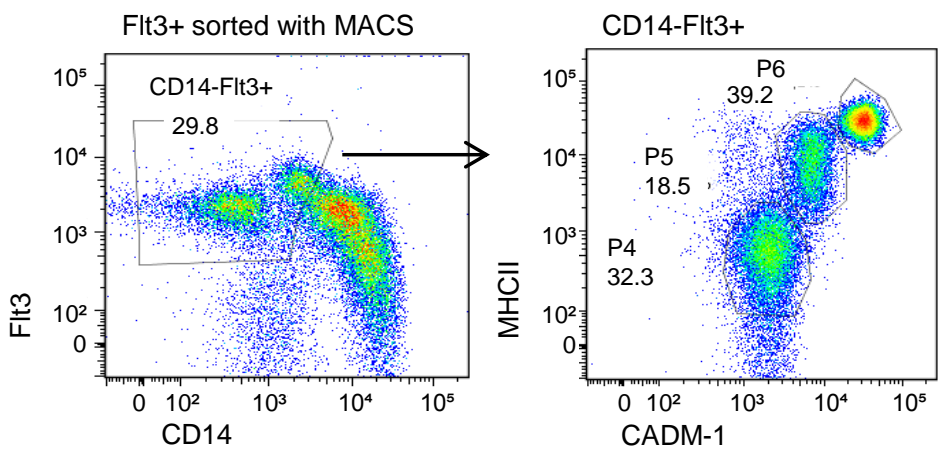

D
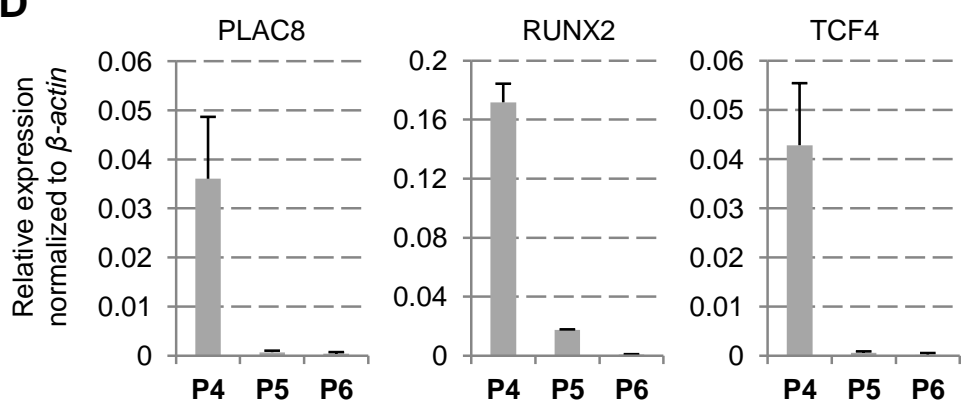